\title{
Military Technology, Geopolitics and Economic Development
}

\section{Mass Factor and Relativist Concern}

The economies of scale in conflict (or the returns to scale in conflict, or military decisiveness, or the mass factor-terms which are used interchangeably in this book), are well-studied by scholars such as Dudley $(1990,1991,1992)$ and Hirshleifer (1995). ${ }^{19}$ It also occupies a prominent position in many grand strategy theories such as that of Wittman (1991). The mass factor measures the relative advantage a larger contestant has over its smaller rival, where a greater mass factor represents a greater relative advantage. If a larger force has a great probability of victory over a smaller force and could do so at little cost, then there is a large mass factor. On the other hand, if a larger force has about the same probability of victory as its smaller foe and victory could only be secured at the expense of great costs, then there is a small mass factor.

Dudley $(1990,1991,1992)$ expounds another way of looking at the concept of economies of scale in conflict: when there are greater economies of scale in conflict, a larger force will suffer fewer casualties when winning victory against a smaller enemy. At the extreme, when the economies of scale in the application of force are infinitely large, a larger force will suffer no casualties when crushing a smaller enemy.

The mass factor is an aggregate technological parameter and does not refer to any specific technological characteristics of the weaponry or the auxiliary system. Examples of increases in the mass factor are the emergence of large standing armies and navies in the $16^{\text {th }}$ and $17^{\text {th }}$ centuries (an emergence that arose due to the military use of gunpowder weaponry which made wars more decisive), and the emergence of the citizen mass army since the French Revolution (as a consequence of rising nationalism which made possible the deployment of troops beyond the personal observational range of officers as nationalistic soldiers are less likely to desert or defect). Technological changes in transportation and infrastructure support systems that enabled a larger body of troops to engage in battles and campaigns increase the economies of scale in conflicts. Likewise, technological advances in communication that

19 Refer to Bush (1974) for related treatment.

(cc) BY-NC-ND 
allowed the coordination of military operations across expansive geographical areas increase the economies of scale of conflict in a geographical sense. ${ }^{20}$ Prior to these advancements in national ideology (for example, nationalism), technology and infrastructure, conflict was conducted on a much smaller scale. Furthermore, the very nature of conflict within the medieval era presented the difficulties of taking of castles and fortified areas and caused medieval conflicts to be long drawn out and indecisive siege warfare. Only until the gunpowder military revolution did the nature of warfare change radically and with it the economies of scale in warfare.

In addition, non-military factors affect the economies of scale in warfare. They could make conquest by the stronger of the weaker more difficult. These factors include racial distribution, linguistic and religious divisions, and geographical features. ${ }^{21}$ For example, India has many languages and ethnic groups, as well as mountain ranges that run in an east-west direction and separate India into the Northern Indo-Gangetic Plain and the Southern India Peninsula. Consequently, India had a smaller mass factor than China under the same military technology and was more difficult to unite or hold together than China, which had greater uniformity in written language and religion.

The economies of scale in conflict further decide how feasible it is to conquer other states and control conquered territory. If the economies of scale in warfare are greater, then conquests and aggrandizements are more likely to happen and continue to expand to spur on further conquests. Therefore within an international political system there will be fewer constituent units and they tend to be larger in size. On the other hand, when there are smaller economies or diseconomies of scale in conflict, a larger force will suffer considerable casualties when winning victory against a smaller enemy. In the extreme case when the economies of scale in the application of force tend to zero, when trying to overcome a smaller enemy, a larger force will have to suffer as many (or even more) casualties as its smaller foe suffers. Under such circumstances, aggrandizement and empire and state building are more costly and are quite impossible. Therefore, the geopolitical landscape tends to be more fragmented when there are smaller economies or diseconomies of scale in warfare.

Another factor affecting the ease of state building is the combined military and economic efficiency of one state relative to that of its rival. This factor

20 Dudley $(1990,1991,1992)$ gives the concept of economies of scale in conflict an extensive treatment and applies it to explain the changes in the territorial size of the states. Hirshleifer $(1989,1991,1995)$ formalizes the concept and analyzes how it shapes the anarchic or hierarchical condition. Refer to Raaflaub and Rosenstein (1999, pp. 364-368) on theories of expansion and contraction of empires.

21 Refer to Hirshleifer (1995). 
measures the relative efficiency of the contestants in conquering and securing contested resources and turning these resources into military capability for further contests. A more asymmetric relative combined military and economic efficiency aids state and empire building and leads to a more uneven distribution of military capability and economic resources. For relative combined military and economic-fiscal efficiency between rivals, efficiency in one area could be enhanced or offset by efficiency or inefficiency in another area. A good example is Sung China which enjoyed overwhelming relative efficiency in the economic area compared to its semi-nomadic semi-agrarian rivals controlling northern China. That advantage however was offset by the overwhelming military efficiency of its semi-nomadic, semi-agricultural northern rivals.

Among the many determinants of relative combined military and economic efficiency is geography. A state controlling an agricultural core area, for instance, will have a greater efficiency in taxation than a state controlling a fragmented hinterland. If there are great economies of scale in warfare, then after rounds of contests, chances are that the state controlling the core area will expand at the expense of the state controlling the fragmented hinterland. This was the experience of war-making and state-making in Europe. A good example was the expansion of the Kingdom of France against the Dukedom of Burgundy.22

Another factor is lines of trade, transportation and communication. States controlling important lines of trade, transportation and communication will have greater relative combined military and economic efficiency. ${ }^{23}$ For example, the Nile River provided substantial economic benefits and served as an important line of transportation and communication in peace or war for ancient Egypt. With the greater relative combined military and economic efficiency accorded by the Nile River, the ancient Egyptian Empire was unchallenged for a long time. It was only with the inventions and uses of horse drawn war chariots and iron weapons in warfare did ancient Egypt face a significant external threat. The Byzantine Empire is another excellent example. Its control of the Black Sea-Aegean Sea trade route through the strategic positioning of its capital, Constantinople, ensured Byzantine dominance over the Eastern Mediterranean regions for more than a millennium. The Byzantine Empire outlasted its Western imperial counterpart of Rome by close to a thousand years.

Asymmetry in relative combined military and economic efficiency could be military in origin as well. Nomads, for instance, have much greater war efficiency than settled societies when cavalry is an important branch of the military. Many of the well-known gigantic empires were established by nomads through

22 Refer to Bean (1973) and Tilly (1992).

23 Refer to Friedman (1977). 
conquests of settled societies: good examples are the Umayyad Caliphate, the Mongolian Empire and the Timurid Empire. The heavy infantry military revolution of the classical era, on the other hand, gave settled agrarian societies with abundant manpower great military advantage. Consequently, the Roman Republic with its abundant and politically-committed manpower had far greater relative combined military and economic efficiency than the other Mediterranean powers, including the Carthaginian maritime trading empire, the Greek republics and the Hellenistic states. A similar story happened in China around the same period, with the establishment of the empire of the Qin and Han Dynasties.

In sum, economies of scale in warfare and asymmetry in relative combined military and economic efficiency help concentrate resources and military capability in the hand of the advantaged contestant. On the other hand, decreasing returns to scale in warfare and symmetry in relative combined military and economic efficiency hinder the consolidation of resources and capability in the hand of a single state. Resources and capability are thereby dispersed among the contestants and a pluralistic international order (which might be a state system) is maintained. ${ }^{24}$

The distribution of relative capability refers to how military capacity is distributed among the contestants. The distribution of relative capability and the mass factor jointly determines the intensity of international military-political competition. The intensity of political military competition is captured by the concept of marginal effect of relative capability, which measures the effect of an additional unit of relative capability on the probability of victory in the contest. For convenience, it is also called relativist concern, or competitive spirit, or a concern for relative capability in this book. It is derived from the contest for power. A key feature of power is that it is relative. Since power is relative, the state therefore views military and economic capability as relative, at least to some extent. States therefore care about their relative strength in military, economic, technological or other fields of human endeavor so long as these have implications for their relative power in international arenas. ${ }^{25}$

Two characteristics of the marginal effect of relative capability are of special interest. One is that it peaks when the two rivals have equal military capability. That is to say, the effect of an additional unit of military capability of contestant 1 on the probability of victory of contestant 1 over contestant 2 is at its greatest when the military capability of contestant 2 is equal to the military capability of contestant 1 . If the difference in capability is too great, then there

24 Refer to Hirshleifer (1995) and Nti (1999, p. 424). Refer to Gilpin (1981) and Hirshleifer $(1988,2000,2001)$ for related discussions.

25 Refer to Grieco (1988a, 1988b, 1990), Gowa (1989), Baldwin (1993), Gowa and Mansfield (1993), Grieco, Powell and Snidal (1993) and Gowa (1994) for related discussions. 
will not be any real contest and anarchy itself might give way to hierarchy. ${ }^{26}$ The more closely matched the two rivals are, the larger the concern for relative military strength. When rivals are equally matched, the incentive to outdo each other is at its greatest. States in the state system where contestants have largely equal military capability are therefore keenly aware of the strategic importance of the relative capabilities of the constituent units. For instance, the concept of balance of power invariably entered the minds of statesmen in the ancient Greek city-state system, the medieval Italian city-state system and the modern European state system. This characteristic of the marginal effect of relative capability curve is what the Hume-Kant hypothesis is about. Another way to look at this characteristic is that an increase in the asymmetry in relative capability reduces the relativist concern or marginal effect of relative capability. For convenience, such a reduction in marginal effect of relative capability is termed a negative asymmetric effect. Conversely, a reduction in the asymmetry in relative capability increases the marginal effect of relative capability. In this case the asymmetric effect is positive.

The second important characteristic of the marginal effect of relative capability is that it is affected by the mass factor. An increase in mass factor has two effects on the marginal effect of relative capability. The first is the scaling effect. Since size now confers greater advantage, there is greater concern for relative military capability. That is to say, given greater economies of scale in conflict, the effect of an additional unit of military capability of contestant 1 on the probability of victory of contestant 1 over contestant 2 is greater. By the scaling effect, given an increase in mass factor, there is an increase in marginal effect of relative capability for both players. The second effect is the unbalancing effect. With greater economies of scale in conflict, the bigger player becomes more powerful and the weaker player weaker. This greater disparity in power between the contestants dampens the competition between them. The unbalancing effect makes both players less concerned about relative capability and reduces the marginal effect of relative capability. That is to say, greater economies of scale in conflict amplify the disparity in power between the contestants and consequently, the effect of an additional unit of military capability of contestant 1 on the probability of victory of contestant 1 over contestant 2 is smaller.

The size of the unbalancing effect depends on the degree of asymmetry in capability between the two contestants. The greater the asymmetry in capability, the greater the unbalancing effect. The unbalancing effect is zero if the two rivals have equal capability since in this situation, their power remains equal whatever the economies of scale in conflict. Therefore, if there is a rough

26 Refer to Hirshleifer (1995). 
balance in the relative capability of the contestants, then an increase in economies of scale in conflict increases the marginal effect of relative capability since the positive scaling effect dominates the negative unbalancing effect. Consequently, when the military capabilities of the two states are roughly equal, an increase in economies of scale in conflict increases the concern for relative capability and the intensity of contest. Conversely, if there is great disparity in the relative capability of the contestants, then an increase in economies of scale in conflict decreases the marginal effect of relative capability since the negative unbalancing effect dominates the positive scaling effect. Consequently, when the military capabilities of the two states are very unequal, an increase in economies of scale in conflict decreases the concern for relative capability and the intensity of the contest.

Of great importance to the main argument of this book is that when the mass factor is large, as the distribution of capability becomes more asymmetric, the marginal effect of relative capability reduces significantly. In other words, when there are great economies of scale in conflict, (that is, size confers great advantage), as the contestants become more unequal in their military capability, the effect of an additional unit of military capability of contestant 1 on the probability of victory of contestant 1 over contestant 2 reduces significantly. On the other hand, when the mass factor is small, that is, size confers little advantage, as the distribution of capability becomes more asymmetric, the marginal effect of relative capability reduces relatively little. In other words, when there are small economies of scale in conflict such that war is indecisive, as the contestants become more unequal in power, the effect of an additional unit of military capability of contestant 1 on the probability of victory of contestant 1 over contestant 2 reduces relatively little. That is to say, the difference in the concern for relative capability between a state system (in which contestants have largely the same level of military capability) and an imperial order (in which the leading power has the overwhelming share of military capability) is greater when the mass factor is larger. For a mass factor that is extremely small, there is practically no difference between an imperial order and a state system in their relativist concern, for in this case, relative capability has very little impact on the probability of victory in a military contest.

The relative power position of a contestant in a political military contest affects not just his relativist concern but also his attitude towards risk. A very weak contestant is in a precarious position and has little to lose and much to gain. The relative power position induces in such a very weak contestant a risk-seeking attitude towards economic decisions or any decision that might affect his power position. On the other hand, a very strong contestant is secure and has little to gain and much to lose. The relative power position induces in such a very strong contestant a risk-averse attitude in economic undertakings, or in any undertaking that has power implications. The weaker the highly 
disadvantaged contestant, the more risk-seeking he is. On the other hand, the stronger the highly advantaged contestant, the more risk-averse that stronger contestant is.

The mass factor affects the risk attitude as a larger mass factor accentuates the disparity in power. A very weak contestant becomes more risk-seeking when there is a larger mass factor and is less risk-seeking when the mass factor is smaller, for given the same disparity in capability, the very weak contestant is in a very perilous state with a larger mass factor, but less so when the mass factor is smaller. Similarly, a very strong contestant is more risk-averse when there is a larger mass factor and is less risk-averse when there is a smaller mass factor, for given the same disparity in capability, the very strong contestant is very secure with a larger mass factor and less so when the mass factor is smaller. Therefore, when there is great asymmetry in relative capability and a large mass factor, the very strong contestant is extremely risk-averse while the very weak contestant is extremely risk-seeking.

Extreme risk-aversion and extreme risk-seeking attitude cause great distortions in economic decisions (especially investment decisions), and create inefficiency in allocation of resources. Instead of choosing to maximize expected returns, the contestant engages in either too much risk taking (if he is risk-seeking) or too little risk taking (if he is risk-averse). A society characterized by extreme risk aversion is one in which most risky investments are shunned, lucrative though they might be. There are hardly any innovations since innovations invariably involve risky investment. The economy is characterized by stagnation, constancy of income and lack of creativity.

An extreme risk-seeking attitude is harmful to the long term prospect of the economy too. A society characterized by an extreme risk-seeking attitude engages in all kinds of risky ventures, unproductive or non-lucrative though these ventures may be. Resources are set aside for such gambles instead of more productive pursuits. Innovations and creativity that take place in such a society tend not to be of the productive kind. Wide fluctuations of fortunes characterize the economy, though there are not many real gains in productive capacity. Such a society has wild vagaries in short-term conditions though no real substantial long-term progress.

The effect of relative power position on risk attitude explains why an imperial order that is very powerful and secure is very conservative and lacks innovation and creativity. The all-encompassing empire, given its preponderant relative capability, has everything to lose and nothing to gain in terms of power. Such an empire is therefore very risk-averse for any innovation would most probably undermine the power position of the empire and is quite unlikely to improve it. The larger the mass factor, the more powerful and risk-averse an all-encompassing empire is. Consequently, a major civilization composed of only a gigantic, uncontestable and universal or almost universal empire will 
exhibit a very different risk attitude when compared to another major civilization that is composed of many equal and independent sovereign states. The civilization with a universal empire will be plagued by risk aversion while the state system civilization will not has such a problem, at least not in its severe form. The effect of relative power position on risk attitude also explains the risky "gambling for resurrection" strategy of states facing greatly adverse conditions in war. ${ }^{27}$ The larger the mass factor, the more risk-seeking these strategically disadvantaged states with a precarious chance of survival will be.

\section{Geopolitics and Economic Performance}

Scholars have long recognized the developmental impact of international political structure. For instance, commenting on the importance of sovereign nation states and the competitive state system to the rise of the West, Wesson (1978) notes:

"Through history, the most important vehicle of competition has been the sovereign state, the supreme organization of society, the great and enduring culture-creating group with which large numbers can identify. Discovery, innovation, productivity, social discipline, and political order have flourished when the sovereign units (which are small enough to arouse feelings of participation yet adequately large to permit the application of available techniques) have been in competition sufficiently strong to engage emotions yet not so desperate as to destroy the rivals. Yet progress is inherently self-limiting because it does away with the conditions that make it possible. The state systems, by virtue of their inventiveness, have made themselves obsolete. Only that of the West managed to hold out for a millennium by expansion and metamorphosis.' (264)

This section analyzes how military technology and international political structure affect economic performance. A competitive state system is an international political system with a large mass factor and a largely symmetrical distribution of capability and resources. The city-state systems of the classical era had many international political systems with a large mass factor but an essentially symmetrical distribution of relative capability and resources. These systems are good examples of a competitive state system, for instance,

27 Refer to Goemans (2000). 
the city-state system of classical Greece, China's Spring and Autumn Era, and the pre-Mauryan state system of India. The cause of such symmetry in relative combined military and economic efficiency could be that there are many core areas of roughly equal sizes, resources and productivity.

In all these international political systems there was constant jockeying for power among the contestants. They are aptly described by the term competitive state systems or competitive city-state systems. Armed conflicts severely affect the fortunes of the states. It is not known for sure who will be the victor. Weak states are constantly being eliminated or reduced to vassal status. For instance, eleventh century Europe had over a thousand principalities. By the time of World War One, only a dozen of them remained. A good example of how a state could disappear was the partitions of Poland by Austria, Prussia and Russia. A once major power of Europe was eliminated due to its inability to match the other states in terms of military capability. ${ }^{28}$

Given the greater economies of scale in conflicts, each state is too small to fully exploit the scale economies as they are trying to expand. Control over resources and large-scale organization are important for the capability of the contestants. The expanding states are crowded together and rivalry among them is very intense. There is a tendency for the constituent units to reorganize through wars and other means to become larger, in order to better exploit the economies of scale in warfare. The number of constituent units is therefore decreasing. If the process of competition continues indefinitely or, if the military capability or the relative combined military and economic efficiency of one contestant is significantly augmented relative to the rest, then the competitive state system will end up being an empire. If a constituent state of the competitive state system gains disproportionate capability relative to the rest, then the momentum of empire building will be set in motion. The delicate balance of power of the competitive state system is hard to maintain and easily disrupted.

In a competitive state system, the constituent member states have acute awareness about power and relative capability in military and economic spheres. There is constant and immense pressure for the states to be powerful. The drive for power and survival makes the states strive to outdo each other in every aspect of human endeavor that affects the power of states in the international arena, with wars and military contests serving as the ultimate test of state power. Comparisons with other states help to goad states from complacency and decay. The possibility of defeat in the international arena haunts the governing elite as defeat brings not only humiliation and losses, but

28 Refer to Tilly (1992). 
the increased likelihood of revolution, coup d'etat and other forms of unrest. Fear of the worst-case scenario-conquest-is the driving force for states to be powerful. There is therefore a strong concern for relative capability.

In a competitive state system, the strong concern for relative capability is a potent developmental force. States try to be more powerful militarily and economically than other states, employing many different measures to enhance their prowess. Entrepreneurial statesmen implement institutional changes to boost the economy and enhance state capacity. Good examples abound in the competitive state system of Europe. For instance, Peter the Great westernized Russia in order to make it a great power. Frederick the Great made Prussia into a centralized military state so as to be able to compete with other European powers. At an earlier time on the other side of Eurasia, the Era of Warring States of China ( $475-221 \mathrm{BC}$ ) provides many good examples as well. At times, development within states can be extraordinarily dramatic: entrepreneurial statesmen may seize power through social upheavals and overhaul the institutional framework, changes that may then generate greater state capacity to cope with the pursuit of power in the international arena. The French Revolution, the Russian Bolshevik Revolution and the Japanese Meiji Restoration are good examples.

The constituent states of a competitive state system do not have extremely risk-averse or risk seeking attitude to significantly distort their economic decisions, thanks to the largely even distribution of power within the competitive state system. The strong relativist concern of the state is therefore translated into great developmental efforts without being significantly distorted by an extreme riskaverse or risk-seeking attitude. Consequently, the intense competition prompts the state to intervene extensively and rationally in the economy to secure a strong economic foundation to support the military machine. The extension of justice by the central government, the substitution of indirect rule with direct rule, and the suppression of feudal wars are examples of measures taken. The state provides public intermediate inputs to boost economic productivity. The share of public intermediate inputs in the economy is high. There are therefore great rational development efforts and achievements in the competitive state system.

An uncompetitive state system is an international political system with a small mass factor and a largely symmetrical distribution of capability and resources. Dense tropical rainforests inhabited by primitive tribes and clans provide a good example of an uncompetitive state system. Given the difficult terrain, there are very small economies of scale in warfare. The distribution of resources and capability among tribes and clans is extremely even, as military conquests and political aggrandizements are constricted by natural geography and climate. The constituent units are separated by severe natural barriers which limit conquests and formation of a unified state. Each constituent unit has expanded to its natural boundary and faces a low level of external threat from the others. Geography, rather than capability and organization efficiency, 
determines the boundaries of the constituent units. The constituent units might not even be contiguous. The relative distribution of military capability among constituent states does not matter much in this environment. ${ }^{29}$

In an uncompetitive state system, there is hardly any struggle among the constituent units for hegemony or supremacy. Nature rather than politics decides the status and power of the states. Armed conflicts are of a small scale and short duration. Weak constituent units or states continue to exist, despite inefficiency in military, economic and other aspects. A good example of an uncompetitive state system was sub-Saharan Africa before the colonial era. There might be some interstate or intertribal conflicts, raids and wars, but given the pre-modern military, transportation and communication technology, as well as the hostile terrain, there was hardly any significant competition among the African states and tribes. Another good example is Oceania before the colonial era. Vast distances across the ocean separated settled societies and states. Though trade and cultural contacts were possible or even frequent, mutual conquests were much more difficult. Consequently, the geopolitical landscape was determined more by geography than by politics.

The uncompetitive state system is rather stable. The conditions for its existence, a small mass factor and an essentially symmetric relative combined military and economic efficiency, are quite common in history. There is no tendency for the system to be united under one empire. Wars might be frequent in the system, but they are likely to be small in scale and, due to the natural geographical conditions, inconclusive-perhaps more raids than wars. State and empire building is difficult given the lesser economies of scale in conflict. The size of the state does not confer much strategic advantage. Control over resources and large organization has no significant effect on the capabilities of the contestants.

In an uncompetitive state system, the constituent member states have little awareness about power and relative capability in military and economic spheres as there is hardly any struggle among them for hegemony or supremacy. Nature rather than politics decides the boundaries between states and the status and power of the states. Weak states continue to exist, despite inefficiency in military, economic and other aspects. Given the highly even distribution of relative capability within an uncompetitive state system, the constituent states do not have extremely risk-averse or risk-seeking attitude that might significantly distort their economic decisions. The relativist concern of the state is therefore being rationally translated into developmental efforts without being significantly

29 If there are very low economies of scale in conflict and public administration, then there will be no state. Refer to Oppenheimer (1975), Tilly $(1975,1992)$, Friedman (1977, 1979), Duffy (1980), Levi (1981, 1988), Best (1982), Blum and Dudley (1989), Blum (1991), Dudley (1991), Wittman (1991), Keegan (1993) and Porter (1994). 
distorted by a strong risk-averse or a strong risk-seeking attitude. However, within an uncompetitive state system, there is hardly any pressure for the states to be powerful. There is no strong relativist concern to act as a drive for developmental effort. There is hardly any drive for power among the states and therefore very little concern for relative capability in state preference. States do not try to be more powerful militarily and economically than other states. There are therefore hardly any development efforts and achievements in the uncompetitive state system.

A stable or uncontestable imperial order is an international political system with a large mass factor and an extreme distribution of capability where the strongest contestant almost monopolizes all military capability and resources within the system. The ancient Egyptian Empire during the bronze era and before the invention and use of iron weaponry and horse-drawn war chariots fits the depiction of a stable imperial order perfectly. After the unification of the Nile River valley under the leadership of Upper Egypt, no viable rival existed to challenge Egyptian power for over a millennium.

In a stable imperial order, there are great economies of scale in warfare and extreme asymmetry in relative combined military and economic efficiency. Consequently, in the steady state equilibrium of continuing conflicts, the imperial regime has expanded to the limits of its natural boundary. Given the large mass factor, the control over resources and large organization is important for military capability. Size confers great advantage in warfare. Since the imperial regime has monopolized or almost monopolized both economic resources and military capability, it is difficult for other players to challenge or contest the imperial order, and consequently the imperial order is quite stable.

The stable imperial order is secure and entrenched. If the core empire suffers defeats and a decline in relative capability, the concentration of resources under its disposal and the greater economies of scale in warfare ensure that the core empire will quickly regain its eminent position. If, under extraordinary circumstances, the imperial regime collapses, the interim or transition period between imperial regimes and dynasties is short. Great economies of scale in warfare and great asymmetry in relative combined military and economic efficiency facilitate the swift consolidation of resources and capability in the hands of an early winner. Empire building gains momentum easily and quickly. For instance, the history of the early Egyptian Empire (before the use of iron weapons and horse-drawn war chariots) was essentially monotonous repetitions of dynastic turnovers.

In a stable imperial order, the imperial regime is very well entrenched and secure and it is extremely difficult for small groups of challengers from within and beyond the border to challenge the imperial power, given the large mass factor. Should the empire reigns supreme, an attitude of arrogance and complacency can instill itself. Since the empire is supreme in its geopolitical niche, a strong economy is not needed for supporting the pursuit of power in the international arena. The concern for relative capability in military and economic 
spheres is almost absent since the empire is all-powerful. The empire therefore feels no need for progress and development. Consequently, the empire extracts resources from the economy for consumption and offers very few public intermediate inputs in returns. The system therefore displays very little developmental efforts or achievements.

In a stable imperial order, given the large mass factor and the extremely high concentration of capability in the hands of the imperial order, the imperial regime has an extremely strong risk-averse attitude while the marginal states and latent challengers have an extraordinarily strong risk-seeking attitude. The extremely strong risk-seeking attitudes and extremely strong risk-averse attitudes severely distort the economic decisions of the imperial regime and the marginal states and are highly detrimental to optimal allocation of resources and development. The system is severely plagued by extreme imperial complacency and conservatism and an extremely low level of rational development effort, given the distortions caused by the extremely strong risk-averse attitude and the extremely weak relativist concern on the part of the imperial regime. The extremely strong risk-seeking attitude and extremely weak relativist concern of the marginal states result in a very low level of rational developmental effort in those states as well.

An unstable imperial order has a small mass factor and an extremely uneven distribution of resources and military capability where the strongest contestant monopolizes almost all military capability and resources within the system. The Srivijaya Empire of pre-modern Southeast Asia fits the description of an unstable imperial order well. Pre-modern Southeast Asia had a very fragmented geography that severely constrained political and military aggrandizement. Dense forests with tropical diseases and vast distances separated by seas made military conquests and unified, centralized political control difficult. Consequently, most of maritime Southeast Asia was in the tribal stage when European colonists first set foot on the islands. Yet, during the late classical and early medieval era, there was a powerful empire in maritime Southeast Asia, the Srivijaya Empire. The Srivijaya Empire was based on southeastern Sumatra, near the coastal city of Palembang, in a strategic location to control the trade between China and India. Given its control over this vital and lucrative maritime trade route, the Srivijaya Empire possessed much higher combined military and economic efficiency than all other maritime Southeast Asian societies. Consequently, the Srivijaya Empire was able to exert its hegemony over present-day Sumatra, Java, Borneo, Malaya, and Riau Islands, and effectively control the Strait of Malacca and the Strait of Karimata. No other nearby state or society came close in terms of capability, resources, or prestige. The language of the Srivijaya Empire, the Malay language, was thus spread throughout maritime Southeast Asia as a lingua franca, a status that it still enjoys today. 
In an unstable imperial order, since there are lesser economies of scale in conflict, sheer size does not confer much strategic advantage. Empire building therefore does not take on its own momentum, and the consolidation of resources in the hands of a single power is not easily achieved. The core empire of the unstable or contestable imperial order tends to control less of their known world compared to that of the stable or uncontestable imperial order. The imperial order is more easily contested by rivals from either within or beyond the borders and is therefore quite unstable.

Relative efficiency in military and economic arenas is significant in deciding the fate of the unstable imperial regime. Should the imperial regime become inferior in combined military and economic efficiency, it will be overthrown by the more efficient challenger. If the contestants are equally matched in combined relative military and economic efficiency, then the system evolves into a state system. Should that happen, the system is then an uncompetitive state system, given the small mass factor. The Srivijaya Empire, for instance, quickly faded into mediocrity after changes in maritime trade routes deprived it of its economic supremacy in the region. Another good example was the Carolingian Empire. The heavy cavalry military revolution reduced the economies of scale in warfare. Given the small mass factor, the Carolingian Empire managed to unite Western Europe only briefly under the charismatic leadership of Charlemagne, but quickly dissolved into an uncompetitive state system after his leadership.

In an unstable imperial order, the pressure for the state to boost the economy for greater revenue to support a more powerful military is quite weak. A strong economy is hardly needed for the pursuit of power in the international arena. The state apparatus therefore remains small and non-interventionist. Since the international hierarchy is clearly in place though weakly enforced, the incentive for jockeying of power is not strong. There is therefore weak relativist concern and drive for development. However, despite its control over most capability and resources, the imperial power is still challengeable by other states due to the small mass factor. A smaller state with greater relative combined military and economic efficiency could significantly challenge the imperial regime. If the gap in combined relative military and economic efficiency persists, the small state will ultimately replace the imperial regime. The fate of the imperial regime does, to a certain extent, depend on relative combined military and economic efficiency. Since size does not confer absolute or overwhelming advantage, and relative combined military and economic efficiency is important, there is some pressure for the imperial regime to be militarily powerful and economically efficient. Therefore a certain level of international competition, latent or apparent, still exists. Consequently, the system exhibits a weak but apparently existent level of relativist concern.

In an unstable imperial order, given the small mass factor and the high concentration of capability in the hands of the imperial order, the imperial regime 
has a very strong risk-averse attitude while the marginal states and latent challengers have very strong risk-seeking attitude. The high risk-seeking attitudes and high risk-averse attitudes severely distort the economic decisions of the imperial regime and the marginal states and are detrimental to optimal allocation of resources and development. The system is plagued by imperial complacency and conservatism and low levels of rational development effort, given the distortions caused by a strongly risk-averse attitude and a weak relativist concern on the part of the imperial regime. The strongly risk-seeking attitude and weak relativist concern of the marginal states also result in a very low level of rational developmental effort.

\section{Major Military Technological Revolutions}

Changes in military technology have been shaping the geopolitical landscape since the earliest eras. The introduction of bronze weapons around $3000 \mathrm{BC}$ changed the method of warfare in Mesopotamia and Egypt. Massive infantry formations, wielding bronze weapons and protected by bronze armor, in conjunction with archers with composite bows, resulted in a considerable increase in the economies of scale in conflict. In the enclosed space of the Nile Valley, the unification of the Egyptian Empire was achieved rather early, ca $3000 \mathrm{BC}$, under the leadership of Upper Egypt. In contrast, the open, fragmented terrain and multiple core areas of Mesopotamia maintained its state system for a further six centuries longer than Egypt. Inter-city rivalry intensified and there was a rise in the construction of massive defensive walls. The greater economies of scale in conflict caused territorial expansion of the political units and consequently, a series of empires were established. ${ }^{30}$ First was the Akkadian Empire, which reigned from 2334-2193 BC. This was followed by the Empire of the Third Dynasty of Ur (2112-2004 BC) and then the Babylonian Empire (ca 1900-1595 BC). The Old Assyrian Empire ruled from around $1830-1741 \mathrm{BC} .^{31}$

The invention of horse-drawn war chariots provided military advantages to peoples on horseback and led to waves of nomadic invasions upon ancient civilizations from around $1700 \mathrm{BC}$. The military use of iron further tilted the combined military-economic efficiency towards the nomads and away from settled societies. As iron utensils and weapons were cheap, in comparison to those

30 Refer to Dudley (1991, p. 47-76).

31 Refer to Haywood (1997, p. 42-43). 
made of bronze, nomads could also afford them. Iron-wielding Hyksos armies defeated copper-armed Egypt around 1600 BC. The more decisive and mobile form of warfare ended the geopolitical isolation of the Egyptian civilization from the rest of the Near Eastern civilizations, thereby creating the Greater Near Eastern international political system.

Around the $9^{\text {th }}$ century $\mathrm{BC}$, horses were bred large enough to allow the emergence of light cavalry on the battlefield. (Light cavalry fights by shooting arrows on horseback while at full gallop, while heavy cavalry depends on the 'shock' of the charge to overwhelm the enemy; light cavalry is only lightly armored or not armored, while heavy cavalry is heavily or fully protected by armor.) Light cavalry units replaced horse-drawn war chariots. This wave of military technological changes resulted in the rise of combined arms legions, where the light infantry made up the bulk of the fighting force and the light cavalry was the important mobile striking force increasing the economies of scale in warfare. The consequence was the emergence of the Pan Near Eastern empires: first it was the Neo-Assyrian Empire, then the Neo-Babylonian Empire and finally the gigantic Achaemenid Persian Empire. In contrast, in the more fragmented or sparsely populated geography of classical Greece, Ganges India and China, warfare was less decisive, and it was the city-state system that emerged first, followed by the territorial state system.

The heavy infantry military revolution of the classical era increased the mass factor. (Heavy infantry relies on engaging the enemy directly in hand-to-hand combat to defeat the enemy, while light infantry fights by skirmishing and delivering missiles to destroy or disrupt enemy formations. Heavy infantry is heavily armored while light infantry is only lightly armored or not armored.) The phalanx formation developed by the Greek city states and then later perfected with the combined Macedonian phalanx and cavalry formations dominated the battlefield. This was then over taken by the introduction of the Roman legions equipped with superior iron weapons and armor. Consequently, the Greek citystate system gave way to the Macedonian Empire, and the Hellenistic state system in turn gave way to the Roman Empire. The rise of the Roman Empire was further aided by the naval revolution related to the use of the triremes. Naval dominance helped Rome to consolidate control over the whole Mediterranean basin. This same process of empire building through use of heavy infantry legions also happened in China. The heavy infantry revolution ushered in the unification of China under the First Emperor, sweeping away the classical state system of China of the Spring and Autumn Era and the Era of the Warring States. ${ }^{32}$

32 Refer to Hui (2005). 
The heavy cavalry revolution tilted the relative military-economic efficiency between settled societies and nomads back towards the latter. Consequently, from around $300 \mathrm{AD}$ to the gunpowder military revolution, waves of nomadsTurks, Tungusics, Mongols and Arabs amongst them-invaded agrarian civilizations and established states and empires around the Eurasian world. ${ }^{33}$ The heavy cavalry military revolution led to the more or less simultaneous collapse or retreat of the classical universal empires in the period 300 to $600 \mathrm{AD}$. The ascendancy of cavalry relative to infantry reduces the economies of scale in the application of force, because cavalry relies less on numerical superiority to win battles. The Roman Empire was divided into two and the western part collapsed under incessant nomadic assaults. ${ }^{34}$ The Gupta Empire of classical India was weakened by nomadic assaults from Central Asia and slowly faded. The Jin Dynasty of China gave up the central plain of North China, which had the dominant share of resources and population, to the nomads and retreated to south of the Yangtze River, where the battle superiority of cavalry was impaired. In place of the massive classical empires came a myriad of tiny states or state-like force-wielding organizations. ${ }^{35}$

Centuries later, the gunpowder military revolution then again raised the economies of scale in warfare. In regions such as China, Japan, India, the Middle East and Central Asia, there was a dominant core area, and the gunpowder empires soon emerged to dominate the political landscape. Medieval fragmentation gave way to the Ottoman Empire in the Middle East and Eastern Mediterranean region, to the Ilkhanate-Timurid-Saffavid Empires and Afshar-Zand-Oajar Dynasties in Persia and Central Asia, to the Delhi Sultanate and Mughal Empire in India, to the Yuan-Ming-Oing Empires in China, and to the Hideyoshi and Tokugawa Shogunates in Japan. On the other hand, in Europe, there were multiple core areas of about the same size. The greater economies of scale in warfare led to the dismantling of feudalism and the rise of national states, but failed to create a pan-European gunpowder empire. During the process of European war-making and state-making, the small and weak states slowly disappeared. For instance, the use of cannon eliminated city-states, such as Siena, that could not afford the expensive, massive and complicated defense fortifications of trace Italian (or star forts) which were better able to withstand siege cannon fire. ${ }^{36}$

33 Refer to Grousset (1970).

34 Refer to Dudley (1992).

35 Refer to Dudley (1991, 1990 and 1992) and Keegan (1993).

36 Refer to Tilly (1992) and Parker (1996). 


\section{Southeast Asia, Africa, America and Oceania}

The waves of major military technological changes discussed in the previous section that swept across the Eurasian landmass had however largely left the non-Eurasian cultures untouched or failed to have any significant impact on their geopolitical landscapes before the early modern era. This has to do with the so called Eurasian dominance in human civilizations. ${ }^{37}$ Therefore this book will focus its analysis on the major Eurasian cultures. However, before starting the main analysis on the major Eurasian cultures, this section will study the various major non-Eurasian cultures and provide a justification for the Eurasian focus. Specifically, it will seek to understand their performance and the reasons behind their failures to be the pacesetters in the history of human civilization. That is to say, this section will shed light on the phenomenon of Eurasian dominance with the theory of this book.

The first half of this section studies pre-modern Southeast Asia, a major cultural and economic crossroads of the Eurasian world. The second half of this section studies how the lack of political military competition affected the history of the non Eurasian world: North and South America, Africa and Oceania. By bringing in the role of military technology and political military competition, the analysis provides additional insights into the phenomenon of Eurasian dominance over the non Eurasian world.

Southeast Asia is in close proximity to both India and China. Southeast Asia is at the crossroads of East Asia and South Asia. Since ancient times there were cultural influences from China, India and since late medieval times, Japan and the Middle East as well. It was from India and China that Southeast Asia received its writing systems and literature; models and concepts of statecraft and social hierarchy; and religious beliefs. Southeast Asia also served as the middle man and maritime commercial exchange hub for trade between East Asia and South Asia and the Middle East. Southeast Asia was connected by extensive intra-regional trade even before the use of writing began in the region.

Constant cultural contacts and economic exchanges with India and China started very early in the classical era. By 500 BC long-distance trade involved both China and India. Southeast Asian rulers took the initiatives to adopt Indian culture and religion starting around 400 AD. ${ }^{38}$ The Maritime Silk Road that linked China with India, the Middle East and Europe went through the seas and lands of Southeast Asia, making Southeast Asia a pivot in the medieval global

37 Refer to Diamond (1997).

38 Refer to Heidues (2000, p. 18, last paragraph and pp. 22-23). 
maritime trading system. ${ }^{39}$ Yet, among the major Eurasian cultures, Southeast Asia was always at the receiving end of cultural influences. Osborne (2000) poses the question this way:

"Why has the Southeast Asian region, despite its size, played so small a part in the shifts of global power over the past two thousand years?" (2)

Since Southeast Asia was a state system throughout its history, by the HumeKant hypothesis, the region should have produced many cultural and developmental achievements to boast of and to contribute to mankind. Yet, throughout its pre-modern history, Southeast Asia had been at the receiving end of cultural and developmental exchanges. There are many explanations for the Southeast Asian failure to be a leader in the history of human civilization: climate, geography, ecology, etc. All might have played a role. However, the most important factor seems to be the lack of intense political-military competition which contributed to the lack of advances in cultural and economic spheres, and thus explains Southeast Asia's failure to be at the forefront of civilization.

Pre-modern Southeast Asia had a very highly compartmentalized geography. Geography rather than international politics determined political boundaries. Jungles, mountains, wild rivers, rough seas and oceans and hot, wet, malarial lowlands formed insurmountable barriers to invaders or settlers. Nearly all of Southeast Asia is tropical, hot and humid and heavily forested, making military operations difficult. During the late classical and early medieval eras, Chinese empires extended only to North Vietnam but ultimately lost that too in the $10^{\text {th }}$ century; the Chola Empire of South India failed to hold on to any foothold for long in Southeast Asia despite its many military actions; Mongol attacks of Vietnam and Java of the second half of the $13^{\text {th }}$ century failed; Ming Dynasty China's effort to re-conquer Vietnam ended disastrously. That is to say, the mass factor of pre-modern Southeast Asia was very small, significantly smaller than that of the major Eurasian cultures given the same military technology.

Before the arrival of the European colonial powers, small mingled tribes and principalities dominated the landscape of these regions. Nature rather than politics defined the geopolitical landscape. $4^{40}$ Borders were defined by natural barriers such as mountains, forests, swamps, rivers and seas. Many of these borderlands were, and indeed still are, inhabited by minorities outside the state structure. Centralized states were late to develop in Southeast Asia and were not the dominant form of political organization in the pre-modern period.

39 Refer to Abu-Lughod (1989).

40 Refer to Fitzgerald (1973, pp. 54-55) and Jones (1981, p. 167). 
In most areas, political integration above the village level was rare..$^{41}$ Given its difficult terrain, the rounds of military technological shocks that swept through the Eurasian landmass had failed to produce a pan Southeast Asian empire.

There were at times powerful and prosperous regional power centers in Southeast Asia. However, the geopolitical landscape was dominated mostly by myriad minor powers and tribes that occupied and were entrenched in their own geopolitical and ecological niche. Pre-colonial Philippines, for instance, had no state structures, and was sparsely populated with a largely kinship and village based political organization..$^{42}$ None of the major centers could expand far beyond their natural niche, much less of establishing a pan Southeast Asian empire. Political competition took the form of border skirmishes and occasional raids into the heartland of rivals, rather than conquests. From the $7^{\text {th }}$ to $13^{\text {th }}$ centuries, there were major power centers in present-day Cambodia, Myanmar, Sumatra and Java. The first Burmese Kingdom known was based in Pagan, and reigned from the $11^{\text {th }}$ century until Pagan was sacked by the Mongols from China at the end of the $13^{\text {th }}$ century. ${ }^{43}$ The most famous power centers of this period were the maritime trading empire of Srivijaya (based in Sumatra) and the land-based agrarian Khmer Empire centered in Cambodia.

The first of these power centers, the Srivijaya Empire, was a coastal trading center and a thalassocracy based in Sumatra. It dominated much of Southeast Asian trade from about the $7^{\text {th }}$ to the $13^{\text {th }}$ century. It was not a territorial state nor was it a power that depended much on military might for its rule. It had no clearly delineated territories nor centralized administrative capacity. Its influence was strongest along the Straits of Malacca, the Karimata Strait (between Borneo and Sumatra) and the Sunda Strait (between Java and Sumatra). Beyond that, its influence took the form of tributary and trading relationships. It was weakened by attacks from the Chola Empire of southern India, and by changing trade routes, which deprived it of its most important source of wealth.

The second of these Southeast Asian power centers was the Khmer Empire, centered on the basin of Lake Tonle Sap. It had a highly developed agriculture which supplied the empire with ample manpower and wealth. At its greatest extent, it controlled much of present-day Thailand, Laos, Cambodia and Southern Vietnam. In earlier periods, Funan, Chenla and Champa were smaller power centers in southern Vietnam and Cambodia preceding the rise of Khmer, but whether or not they qualify as "states" is questionable. ${ }^{44}$

41 Refer to Heidhues (2000).

42 Refer to Church (2006, p. 125).

43 Refer to Church (2006, p. 110).

44 Refer to Heidhues (2000, pp. 23-34) and Sardersai (2003, pp. 22-50). 
After the collapse of the Srivijaya and Khmer empires, the major powers between the $14^{\text {th }}$ and $18^{\text {th }}$ centuries were: Myanmar under the rulers of Pegu and then Ava (near Mandalay) (1364-1752 AD); Vietnam under the Later Le Dynasty (1428-1788 AD); the Thai Kingdom of Sukhothai and then the Ayuthaya (or Ayudhya) based on the Chao Phraya River delta (1351-1767 AD); Vietnam, which had gained independence from China in the $10^{\text {th }}$ century and was expanding to the south; the Majapahit Empire, centered on Eastern Java and Bali (1292-ca 1527 AD); and the Sultanate of Malacca (Melaka), centered on the Malay Peninsula (ca 1400-1511 AD). The Sultanate of Malacca succeeded Srivijaya's role as a maritime trading power, while the other major power centers were land-based and agrarian. The Sailendras and Mataram rulers of Java were the other powers that preceded the Majapahit Empire. ${ }^{45}$ Additionally, there was a galaxy of smaller states, some quite powerful. Among the minor powers were the sultanates of Acheh, Brunei, the Malukas and Sulawesi, and the Kingdom of Cambodia.

None of these Southeast Asian powers however could overpower the rest to establish a pan Southeast Asian hegemony or imperial realm, despite changes in military technology throughout pre-modern history. Compared with other major cultures of the Eurasian landmass, Southeast Asia remained throughout its pre-modern history an international political system dominated by small states and tribes with a low level of political-military competition between the major constituent units, due to the small mass factor. The low-level competition within the system caused Southeast Asia to be a follower of the other major cultures in terms of advances in human civilization, despite its size and resources. All pre-modern major Eurasian civilizations had larger mass factors than pre-modern Southeast Asia. The geography of Southeast Asia was much more fragmented compared with that of the major Eurasian cultures. Pre-modern Southeast Asia therefore had lower relativist concern than the major Eurasian cultures, despite its highly equal distribution of capability. Consequently, pre-modern Southeast Asia failed to play a more important role in the history of civilizations.

Like Southeast Asia, the non-Eurasian cultures also failed to be at the forefront of human civilization. Diamond (1997) argues that the dominance of Eurasia is based mainly on its ecology, biology and natural geography. ${ }^{46}$ Eurasia is laid primarily over the west-east axis, while the North America-South America landmass and Africa have north-south as the main axis. This, together with Eurasia's large area, results in wider continuous ecological areas in Eurasia compared with other landmasses. There were therefore more Eurasian plant

45 Refer to SarDesai (2003, pp. 51-62).

46 Crosby $(1972,1986,1994)$ has applied the same approach and analyzed the impact of human activities on the global ecology on a world historical perspective. 
and animal species suitable for domestication and more opportunities for the peoples of Eurasia to exchange both innovations and diseases.

The east-west orientation of Eurasia allowed breeds domesticated in one part of the continent to be used elsewhere through similarities in climate and the cycle of seasons. Australia, in contrast, though it also has an east-west orientation, suffered from a lack of useful animals due to mass extinctions. Due to the northsouth main axis of the North and South American landmass, the peoples of the Americas had difficulties adapting crops domesticated for use at other latitudes. Africa was fragmented into many economic sub-areas due to the extreme climatic variations from north to south: in both Africa and the Americas, plants and animals that flourished in one area never reached other areas where they could have flourished, because they could not survive the intervening environment. Therefore domesticated plants and animals and technology spread much faster in history inside Eurasia compared to other continents. Hence Eurasia was able to support larger, denser populations, which made trade easier and technological progress faster than in other regions. These economic and technological advantages eventually enabled Eurasians, and ultimately Europeans, to conquer the peoples of the other continents in recent centuries.

The presence of large animals capable of being domesticated to be raised for meat, work, and long-distance communication and transportation further enhanced the advantage of Eurasia relative to other landmasses. The five most useful species of domesticated large animals- cow, horse, sheep, goat, and pig are all indigenous to Eurasia. This livestock helped with the spread of agriculture and eventually cities, and consequently, Eurasia had denser populations with a higher level of trade. There were also more people living in close proximity to livestock. Diseases were transmitted more easily and so natural selection forced Eurasians to develop immunity to a wide range of pathogens. Therefore, when Europeans made contact with the Americas, European diseases ravaged the Native American population, rather than the other way round. So it was easier for relatively small numbers of Europeans to conquer much larger indigenous populations.

Two of Diamond's (1997) arguments are especially relevant to the main argument of this book: the main axial orientations of the continents and the availability of large domesticated animals for long-distance transportation. The combined continent of the Americas is the largest of all the non-Eurasian regions, about four-fifth the size of the Eurasia land mass. Supposedly the combined continent of the Americas should be a close rival of Eurasia in the progress of human civilizations. Yet, the reality is far from that. The main reason is that the main geographical orientation of the Americas is from north to south. This made travel and conquest difficult during pre-modern times as the travelers or conquerors had to overcome differences in climate. This, together with the lack of large domesticated animals for transportation, resulted in lower economies of scale in warfare. There was no contact between the civilization in 
Peru and those in Meso-America. ${ }^{47}$ Therefore, once the Aztec and Inca empires were established in Meso-America and the Peruvian highland, there was hardly any political-military competition in America. The lack of any significant political-military competition resulted in a very low relativist concern. Furthermore, metallic weapons were not used in warfare in the Americas until the arrival of the Europeans. Warfare therefore had very low military decisiveness and relativist concern was very low consequently. The very high concentration of capability in these two empires resulted in highly risk-averse power-induced risk attitude too. Consequently, complacency and conservatism plagued the pre-modern American civilizations and there was no drive for further progress.

Africa too has a north to south main geographical orientation. Pre-modern sub-Saharan Africa was covered by thick forests, and there were diseases conquered only recently by modern medicine. Some of these diseases were not even conquered yet. All these obstacles resulted in a small mass factor. Therefore civilization and state building started very late, despite Africa's proximity with the first civilizations of the ancient Near East. The pre-modern states or empires in Africa were localized and not contiguous with each other; the political units interacted sporadically and marginally. Due to the very small mass factor, pre-modern Africa had a very low relativist concern. Consequently, there was very little drive to propel the progress of civilization in Africa.

Australia and Oceania were characterized by external and internal isolation in pre-modern eras. In fact, these regions were the most isolated of all major regions. A sparse population was separated by vast distances, which resulted in very low economies of scale in warfare. Political-military competition was almost nonexistent. Most of the region was still at the hunter-gatherer stage when incorporated into the Europe-centered modern world state system in around the $18^{\text {th }}$ century. The extremely low mass factor generated extraordinarily low relativist concern, even though the distribution of resources and capability was highly even. Military technology was still at the pre metallic stage too which further contributed to an extremely low relativist concern. Consequently, there was practically no drive generated by political-military competition to propel the progress of civilization.

In sum, the brief survey of the experiences of Southeast Asia, Africa, the Americas and Oceania reveals the importance of political military competition in affecting advances of economy and civilization. The lack of political and military competition explains the failures of these diverse, large and resource-abundant regions to set the pace of civilization in human history. The result is the so called Eurasian dominance in human civilizations.

47 Refer to Diamond (1997). 


\section{The Three Strands of Hume-Kant Hypothesis}

Political military competition pressures states to keep pace with if not overtake one another in economic performance and technological and institutional improvements. The other two mechanisms of Hume-Kant hypothesis also bring forth such beneficial outcomes. Cultural diversity and exchanges, economic freedom and mobility of factors of production across national boundaries and the liberal constraints that such freedom and mobility imposed on the predatory tendency of the state, enhances economic performance and technological and institutional progresses as well. Though focusing on the effects of military technological changes and political military competition on geopolitics and economics, this book is not espousing a mono-causal theory of political military competition determining economic performance. Other factors and mechanisms definitely have their effects too. Rather, the emphasis on political military competition is for expositional convenience and clarity. Readers interested in the working of the other two mechanisms might want to refer to Bernholz et al. (1998) and Bernholz and Vaubel (2004) and the works cited there.

Another reason for focusing on political military competition is that the working of the other two mechanisms of Hume-Kant hypothesis, namely, cultural and institutional creativity and diversity and, factor mobility across international boundaries, also critically depends on military technology and political military competition between states. There are two major preconditions for cultural diversity and exchanges, and institutional and policy innovations and imitations to work. Firstly, there must be more than a single state around. Secondly, there must be significant competition between states for them to be interested to innovate to get ahead of other states, or to imitate to catch up or stay on par with other states. Military technology, by affecting the geopolitical landscape and the intensity of political military competition between states, significantly decides the decree of cultural innovation and competition between states.

Military technology, by affecting the geopolitical landscape, influences the number and size of states within a particular geographical region. That fundamentally decides the possibility of mobility of factors of production across state boundary. There will be greater mobility of factors of production across state boundaries if there is keen policy competition between states to lure more factors to their territory so as to enlarge the tax base, which would occur if there is intense political military competition. ${ }^{48}$ Political military drives states to trade and increase their resources and capability. A good example

48 Refer to Alesina, Spolaore and Wacziarg (2000). 
was that mercantilism became the guiding principle of many states in the early modern competitive European state system. Another good example was China during the Spring and Autumn Era and the Era of the Warring States when China produced its own mercantilists, including Guan $\mathrm{Zi}$ and Lu Bu Wei. Under the premiership of Guan $\mathrm{Zi}$, the Kingdom of Oi during the Spring and Autumn Era actively encouraged commerce and gave merchants many preferential treatments. These policies laid down the economic foundation for the Kingdom of Qi to emerge as the first of a series of hegemonic powers during the Spring and Autumn Era. Similarly, the policies of premier Lu Bu Wei during the Warring States Era greatly enhanced the power of the Kingdom of Oin and facilitated the unification of China under the First Emperor. Another good example of how the concern for power affected the trade policy of the state was Sassanian Persia's conquest of Yemen. The move had the intended purposes of blocking the Roman-Indian trade, to weaken the Roman Empire and profit the Sassanian Empire.

A further reason for focusing on political military competition is that there are reasons to believe that it has a stronger effect on the very long term economic performance of a major culture than the other two mechanisms of HumeKant hypothesis. Transportation and communication means and technology are necessary for the working of all three mechanisms, and factors that contribute to one often will help in the working of the other two too. In terms of requirements of transportation and communication capacity, cultural and economic exchanges are less demanding than political-military conquests. Military conquests require not only movements of troops and supplies across geographical space and barriers, but also overcoming the resistance of the defending forces. Therefore, the existence of severe political-military competition means that if states are already in such close proximity, given the technological and geographical conditions, cultural and economic exchanges will be at a very high level, so long as state policies and political factors do not inhibit them. All major cultures therefore have had substantial economic exchanges within their respective geographical regions throughout known history. It was the type of international political structure that differed across time. If a high level of political-military competition existed, then so would a high level of cultural and economic exchange. Therefore a priori theoretic reasoning points to political-military competition as the main force driving the variations in very long term economic performance through time.

The case of pre-modern Southeast Asia and the other cases of non Eurasian cultures provide the empirical justification for the emphasis on the political-military competition strand of the Hume-Kant hypothesis. Since pre-modern Southeast Asia and many of the other non-Eurasian cultures (such as those in Africa and America) enjoyed a high factor mobility amongst their constituents units and yet failed to be at the forefront of human civilization historically, there is therefore a good cause to focus on the political military competition 
mechanism to explain variations in very long term economic performance among the major cultures, especially those of the Eurasian rim lands. To this task the remaining chapters of this book devote themselves to. 